\title{
The values shown on optical technology-based patient monitors must be cautiously interpreted: intravenous dye-induced errors
}

\author{
Hee-Pyoung Park \\ Department of Anethesiology and Pain Medicine, Seoul National University Hospital, Seoul, Korea
}

Intravenous dyes such as indocyanine green (ICG), indigo carmine, and methylene blue are commonly used during various surgical procedures. The intraoperative administration of intravenous dyes can result in misreadings of the actual values measured by optical technology-based patient monitors (i.e., cerebral oximeters and pulse oximeters) because they interfere with the amount of the specific infrared or red wavelength detected by each device. Therefore, clinicians would benefit from a narrow review of the effects of intravenously administered dyes on regional cerebral tissue oxygen saturation and percutaneous oxygen saturation readings.

The pulse oximeter was developed based on the fact that oxygenated and reduced hemoglobin have different rates of absorption of red and infrared light (Lambert-Beer law). Oxyhemoglobin absorbs more infrared light $(990 \mathrm{~nm})$, whereas deoxyhemoglobin absorbs more red light $(660 \mathrm{~nm})$. The device detects the difference in the extent of absorption of two wavelengths of light (660 and $925 \mathrm{~nm}$ ) in arterial blood. The value is automatically calculated as an absorption ratio (extent of light detected at $660 \mathrm{~nm} /$ extent of light detected at $925 \mathrm{~nm}$ ) and is represented as the arterial oxygen saturation $\left(\mathrm{SaO}_{2}\right)$. Similar to pulse oximetry, cerebral near-infrared spectrometry measures the absorption ratio of two different wavelengths of near-infrared light (730 and $805 \mathrm{~nm}$ ) in venous, capillary, and arterial blood and represents the value as the regional cerebral tissue oxygen saturation $\left(\mathrm{SctO}_{2}\right)$.

Corresponding author: Hee-Pyoung Park, M.D., Ph.D.

Department of Anethesiology and Pain Medicine, Seoul National University Hospital, 101, Daehak-ro, Jongno-gu, Seoul 110-744, Korea Tel: 82-2-2072-2466, Fax: 82-2-747-5639

E-mail: hppark@snu.ac.kr

Korean J Anesthesiol 2015 April 68(2): 97-98

http://dx.doi.org/10.4097/kjae.2015.68.2.97
In clinical practice, intraoperative ICG is commonly used during neurosurgery to confirm the patency of the anastomosed vessels after middle cerebral artery-superficial temporal artery bypass surgery or carotid endarterectomy and the completeness of the secured aneurysm after cerebral aneurysmal clipping. The peak absorption wavelength of ICG is $805 \mathrm{~nm}$ [1]. A clinical study published in this issue of the Korean Journal of Anesthesiology demonstrates that the intravenous injection of ICG can produce false increases in $\mathrm{SctO}_{2}$ readings in a dosedependent fashion [2]. This finding can be partly explained by an increase in the absorption ratio of two different wavelengths of light: 730 and $805 \mathrm{~nm}$. In other words, ICG absorbs light with a wavelength of $805 \mathrm{~nm}$, falsely decreasing the amount of 805 $\mathrm{nm}$ light detected by the cerebral oximeter; this light is displaced as an increased $\mathrm{SctO}_{2}$ reading. Another recent study showed that intravenous ICG administration caused a false decrease in $\mathrm{SaO}_{2}$ readings [2,3]. ICG acts similarly to deoxyhemoglobin in arterial blood; this falsely decreases the absorption ratio of red and infrared wavelengths detected by the pulse oximeter, resulting in a decreased $\mathrm{SaO}_{2}$ reading.

Indigo carmine is commonly used during urologic surgical procedures to identify the ureteral orifices in the bladder. Indigo carmine is a blue dye with peak absorption at around $620 \mathrm{~nm}$ [1]. Therefore, intravenous indigo carmine administration, like ICG injection, causes a false decrease in $\mathrm{SaO}_{2}$ readings by decreasing the amount of red light $(660 \mathrm{~nm})$ detected by the pulse oximeter. In contrast to ICG, however, indigo carmine administration results in a false reduction in $\mathrm{SctO}_{2}$ readings by decreasing the amount of light with a wavelength of $730 \mathrm{~nm}$ detected by the cerebral oximeter [4]. Methylene blue, which is used to treat vasoplegic syndrome in clinical practice $[5,6]$, has an absorption peak at $668 \mathrm{~nm}$ and shows a dose-dependent effect on plasma light absorbance, resulting in falsely low values on pulse oxim-

(c) This is an open-access article distributed under the terms of the Creative Commons Attribution Non-Commercial License (http://creativecommons.org/ licenses/by-nc/3.0/), which permits unrestricted non-commercial use, distribution, and reproduction in any medium, provided the original work is properly cited. 
eters and cerebral oximeters $[7,8]$.

In conclusion, clinicians should be aware that the intraoperative administration of various dyes can cause misreadings of the actual values measured by optical technology-based patient monitors, including cerebral oximeters and pulse oximeters, by interfering with the amount of the specific infrared or red wavelength detected by each device.

\section{References}

1. Scheller MS, Unger RJ, Kelner MJ. Effects of intravenously administered dyes on pulse oximetry readings. Anesthesiology 1986; 65: 550-2.

2. Baek HY, Lee HJ, Kim JM, Cho SY, Jeong S, Yoo KY. Effects of intravenously administered indocyanine green on near-infrared cerebral oximetry and pulse oximetry readings. Korean J Anesthsiol 2015; 68: 122-7.

3. Yoo KY, Baek HY, Jeong S, Hallacoglu B, Lee J. Intravenously administered indocyanine green may cause falsely high near-infrared cerebral oximetry readings. J Neurosurg Anesthesiol 2015; 27: 57-60.

4. McDonagh DL, McDaniel MR, Monk TG. The effect of intravenous indigo carmine on near-infrared cerebral oximetry. Anesth Analg 2007; 105: 704-6.

5. Evora PR, Levin RL. Methylene blue as drug of choice for catecholamine-refractory vasoplegia after cardiopulmonary bypass. J Thorac Cardiovasc Surg 2004; 127: 895-6.

6. Levin RL, Degrange MA, Bruno GF, Del Mazo CD, Taborda DJ, Griotti JJ, et al. Methylene blue reduces mortality and morbidity in vasoplegic patients after cardiac surgery. Ann Thorac Surg 2004; 77: 496-9.

7. Mittnacht AJ, Fischer GW, Reich DL. Methylene blue administration is associated with decreased cerebral oximetry values. Anesth Analg 2007; 105: 549-50.

8. Sidi A, Paulus DA, Rush W, Gravenstein N, Davis RF. Methylene blue and indocyanine green artifactually lower pulse oximetry readings of oxygen saturation. Studies in dogs. J Clin Monit 1987; 3: 249-56. 